\title{
Research Paper: Sociodemographic Determinants of Marital Satisfaction Among an Iranian Population
}

\author{
Farahnaz Bahrami $^{1}$ (D), Vajihe Armanmehr ${ }^{2}$ (D), Shahab Rezaeian ${ }^{3}$ (D), Ali Alami ${ }^{4}$ (D), Akram Kharazmi ${ }^{*}$ (i)
}

1- Department of Educational Sciences and Psychology, School of Consulting, Shahid Chamran University of Ahvaz, Ahvaz, Iran.

2- Social Development \& Health Promotion Research Center, Gonabad University of Medical Sciences, Gonabad, Iran.

3- Research Center for Environmental Determinants of Health (RCEDH), Kermanshah University of Medical Sciences, Kermanshah, Iran

4- Department of Epidemiology and Biostatistics, School of Public Health; Social Determinants of Health Research Center, Gonabad University of Medical Sciences, Gonabad, Iran.

5- Department of Nursing, School of Nursing, Kashmar, Mashhad University of Medical Sciences, Mashhad, Iran.

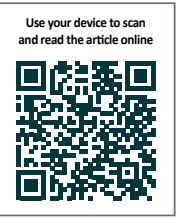

Citation Bahrami F, Armanmehr V, Rezaeian Sh, Alami A, Kharazmi A. Sociodemographic Determinants of Marital Satisfaction Among an Iranian Population. Journal of Research \& Health. 2021; 11(3):183-190. http://dx.doi.org/10.32598/ JRH.11.3.100.5

doit: : http://dx.doi.org/10.32598/JRH.11.3.100.5

\section{(c) (1) (8)}

Article info:

Received: 13 Feb 2019

Accepted: 16 Jan 2021

Publish: 01 Jun 2021

\section{Keywords:}

Marital satisfaction, Satisfaction, Relationships

\section{A B S T RACT}

Background: There is a lack of Iranian studies on marital satisfaction, which is one of the important factors in the stability of marriage. Therefore, the present study aimed to evaluate the effects of sociodemographic variables on marital satisfaction.

Methods: This analytical and cross-sectional study was conducted on 770 married people from Gonabad City, Northeast of Iran. The simple random sampling method was used. Also, the ENRICH marital satisfaction scale was used to measure marital satisfaction as a dependent variable. A cut-off score of 100 was considered for the scale, with higher scores indicating satisfaction. Moreover, the logistic regression model was used to examine the effects of the variables on marital satisfaction.

Results: The Mean \pm SD age of the participants was $39.2 \pm 10.6$ years. Most of the participants $(75 \%)$ were categorized as satisfied, with a Mean \pm SD score of $113.9 \pm 26.8$. Besides, both univariate and multiple regression analyses showed a strong significant relationship between economic status and marital satisfaction, ie, a better economic status increased the odds of marital satisfaction. After controlling other investigated variables, the logistic regression model showed that men are about two times more likely than women to be satisfied with their marriage (adjusted odds ratio $=1.82$ ).

Conclusion: The present findings showed that family income and gender positively influence marital satisfaction. Accordingly, marital satisfaction and family solidarity could be enhanced by the provision of legal and social rules to ensure the equal right of men and women, as well as attempts to improve the economic status of the families.

\section{Corresponding Author:}

Akram Kharazmi

Address: Social Determinants of Health Research Center, Gonabad University of Medical Science, Gonabad, Iran

Phone: +98 (51) 57229025

E-mail: kharazmia3@mums.ac.ir 


\section{Introduction}

arriage is known as the most important event in the life of each person after $\mathbf{M}$ birth. Many studies have shown the positive effect of marriage on physical and mental health, as married people reported better health status and longer life span, compared with single individuals [1]. Marriage and marital relationships develop intimacy and pleasure for both men and women. Many people prefer seeking pleasure instead of working, cronyism, and having children [2]. Marital satisfaction means the matching expectations of married life and real-life experiences [3]. Marital satisfaction is the adaptation between people's present situation in marital relationships and their expected situation [1]. This directly or indirectly relies on family or spouse support and improved quality of life, whereas marital dissatisfaction may lead to stress, anxiety, and potentially divorce [4]. Family health and well-being have been shown as important measures of a country's well-being [5]. Over the past few decades, the formation of marriage and crucial factors that determine the success or failure of marriage have become the major concerns of psychologists [6].

Many crucial factors have been shown to influence marital satisfaction, including the level of intimacy, spontaneous cognition in response to partner behavior, personal characteristics, couple's education, the existence of children, marriage age, marriage duration, and the spouse's economic status. Other factors affecting marital satisfaction include the spouses' expression of affection and the amount of time spent together. In addition, factors related to marital satisfaction from the spouses' point of view include sexual satisfaction, the division of household tasks, or view of gender roles [7].

Guo and Huang reviewed several studies on marital happiness and concluded that marital satisfaction varies based on important variables, such as the stage of the family life cycle, which include factors, such as the number and age of the children and the occupational status of spouses [8].

Many studies have shown a significant gender difference in marital satisfaction. For example, a study in Tehran indicated that the average level of marital satisfaction among male participants was significantly higher than that of female participants, while a negative correlation was observed between gender and marital satisfaction among female participants. However, education and the number of children were also positively correlated with marital satisfaction [9].

Factors that contribute to marital satisfaction may differ across cultures. As such, evidence shows a significant negative correlation between marital satisfaction and the number of children in Turkey, Britain, and the United States. Besides, length of marriage was negatively associated with marital satisfaction. In these countries, men were more likely to marry younger women, also, older men and women reported a higher rate of marital satisfaction [10]. Aghajanian (1986) also stated that Iranian men tended to marry younger women, and wives' older age increased the rate of divorce [11]. The findings of the previous studies have shown a negative association between marital satisfaction and the number of children [12]. A logical reason to study marital satisfaction is to understand the role of marital satisfaction in the family and individual life [13]. As such, when a successful marriage is established, the need to develop an intervention to prevent or lower adverse marital outcomes or divorce is reduced [14].

Since marital dissatisfaction is considered to be a possible condition for divorce, researchers need to be informed of demographic factors in finding ways to increase marital satisfaction. Identifying the associated factors of marital satisfaction is particularly valuable in Iranian couples, where divorce is more indecent. On the other hand, different reports about factors contributing to marital satisfaction are inconsistent.

A limited number of studies examined the relationship between demographic characteristics and marital satisfaction in Iranian couples. Therefore, the present study aimed to evaluate the effects of demographic variables, such as gender, husband and wife age, education, the number of children, occupational status, marriage age, and economic status on marital satisfaction.

\section{Methods}

This analytical and cross-sectional study was conducted on 770 married people from Gonabad City, Northeast of Iran. Based on previous studies [15], the sample size was estimated to be 660 subjects, with an error level of 0.05 . Given the potential future problems, the sample size was increased to 770 .

After obtaining permission from corresponding supervisors, a list of married people was extracted from the Census Bureau in health centers. Then, assuming a 1:1 gender ratio, samples were randomly selected from the 
list through the convenient sampling method. All participants were invited to health centers to complete the questionnaires. Those who were unable to refer to health centers completed the questionnaires at their homes or workplace verbally (for illiterate participants) or written.

\section{Instruments}

Two different questionnaires were used as follows:

The Sociodemographic Questionnaire: This form was designed by the principal researcher to obtain sociodemographic background information, such as the respondent's age, gender, education, date of marriage, number of children, and spouse's age and education, and gather some additional sociodemographic variables.

The ENRICH Marital Satisfaction (EMS) Scale: The EMS scale is a 115-item questionnaire comprising a marital satisfaction scale. In this study, the 47-item EMS scale was used to measure marital satisfaction as a dependent variable. It is scored on a 5-point Likert scale. The highest score for the EMS is 235. The higher the score, the more satisfied a person is with his/her marriage. The scale items were rated on a 1-to-5 agree-disagree response scale as follows: completely agree, agree, no idea, disagree, and completely disagree. A cut-off point of 100 was considered for the marital satisfaction scale so that people with a score of less than 100 were defined as dissatisfied (code 0 ) and those with a score of 100 or higher were defined as satisfied (code 1) [16].

\section{Data analysis}

The obtained data in this study were analyzed by descriptive statistics for the demographic characteristics. As such, mean and standard deviation were used for quantitative variables, and frequency and percentage were used for qualitative variables. Also, univariate and multiple logistic regression analyses were used to examine the effects of the variables on marital satisfaction. Data analysis was performed at a 95\% confidence level using the Stata software, version 14 (StataCorp, College Station, TX, USA). Besides, the ethical approval of the study was obtained from the Research Ethics Committee of the Gonabad University of Medical Sciences (IR. GMU.REC.1394.55).

\section{Results}

The Mean \pm SD age of the participants was $39.2 \pm 10.6$ years. Among participants, $50.8 \%$ were male, $32.2 \%$ had under high school diploma education, and $33.2 \%$ had ac- ademic educations. Also, 54.9\% of the participants were employed, 9.1\% had no children, and 33.3\% had more than three children. Moreover, $15.2 \%$ of the participants reported low economic status, and the length of marriage was more than 15 years in $54.6 \%$ of the respondents. Moreover, the Mean \pm SD score of marital satisfaction was $113.9 \pm 26.8 ; 75 \%$ of the participants were categorized as maritally satisfied. Table 1 shows more details on the sociodemographic characteristics of the participants.

Table 2 reports the crude and adjusted odds ratios of the demographic characteristics. Univariate analysis showed a strong significant relationship between economic status and marital satisfaction, ie, better economic status increased the odds of marital satisfaction. Also, marital satisfaction was positively correlated with marriage age and educational level, however, this relationship was not statistically significant. After controlling for gender, occupational status, and marriage age, the economic status was significantly associated with marital satisfaction. The results of multiple regression analysis showed that gender (adjusted odds ratio=1.82) was significantly correlated with marital satisfaction $(\mathrm{P}=0.049)$. As such, men were more likely than women to be satisfied with their marriage.

According to Table 2, marital satisfaction is not significantly related to age, education, occupational status, number of children, and length of the marriage. Thus, hypotheses 2,3 , and 5 are accepted and hypothesis 4 is rejected. Gender and economic status were significantly associated with marital satisfaction, thus, hypotheses 1 and 3 were accepted

\section{Discussion}

According to the findings of this study, gender was significantly associated with marital satisfaction. As such, the rate of marital satisfaction was higher in men than in women; this result was consistent with the previous studies [17-19]. This may be because men acquired such a dominant position in authoritarian families [20]. Generally, men's dominant position in the society, the customary legal laws and rights that are given to men, and gender inequality in Iran are associated with higher marital satisfaction among men.

Individual and social freedom; customary and community rights; and legal rights, such as the right to take care of women and children, polygamy, residence, and divorce for men allow them to satisfy their needs without any concerns regarding social judgments and legal convictions. The findings of the present study also reveal that the economic status is significantly associated with 
Table 1. Sociodemographic characteristics of the population in Gonabad City, northeast of Iran, 2015

\begin{tabular}{|c|c|c|}
\hline Variable & Subgroup & No. (\%) \\
\hline \multirow{3}{*}{ Gender } & Female & $325(50.8)$ \\
\hline & & \\
\hline & Male & $315(49.2)$ \\
\hline \multirow{3}{*}{ Age group, $y$} & $<45$ & $469(73.4)$ \\
\hline & & \\
\hline & $>45$ & $170(26.6)$ \\
\hline Age, y (Mean $\pm S D)$ & & $39.20 \pm 10.6$ \\
\hline \multirow{3}{*}{ Education level } & Under diploma & $207(32.2)$ \\
\hline & Diploma & $222(34.6)$ \\
\hline & Academic & $213(33.2)$ \\
\hline \multirow{3}{*}{ Occupation } & Employed & 317 (54.9) \\
\hline & & \\
\hline & Unemployed & $260(45.1)$ \\
\hline \multirow{3}{*}{ No. of children } & 0 & $58(9.1)$ \\
\hline & $1-2$ & $368(57.6)$ \\
\hline & $\geq 3$ & $213(33.3)$ \\
\hline \multirow{3}{*}{ Duration of marriage, $y$} & $<15$ & 347 (54.6) \\
\hline & & \\
\hline & $>15$ & $289(45.4)$ \\
\hline \multirow{5}{*}{ Age at marriage, $y$} & $<21$ & $143(22.5)$ \\
\hline & $21-30$ & $401(63.0)$ \\
\hline & & \\
\hline & $31-40$ & 73 (11.5) \\
\hline & $>40$ & $19(3.0)$ \\
\hline \multirow[t]{2}{*}{ Age at marriage, $y($ Mean $\pm S D)$} & & $25.3 \pm 6.4$ \\
\hline & Low & $96(15.2)$ \\
\hline \multirow[t]{2}{*}{ Self-reported income } & Moderate & $264(41.8)$ \\
\hline & High & $271(43.0)$ \\
\hline \multirow{3}{*}{ Marital satisfaction } & No & $162(25.0)$ \\
\hline & & \\
\hline & Yes & $483(75.0)$ \\
\hline
\end{tabular}

mPA

marital satisfaction; this finding complied with the previous studies [14, 21-23]. It is important to note that physiological needs, such as living place, food, and clothing are provided by money. Thus, money can fulfill physiological, safety, and even social needs [24]. Furthermore, according to the Maslow hierarchy of needs theory, the satisfaction of an individual is met toward the fulfillment of financial needs. Also, Burgess and Lock stated that financial assistance and economic status are contributors to marital satisfaction or divorce [3]. Those couples seeking divorce cited financial problems as a major contributor to divorce [25]. On the other hand, better economic status and financial well-being are associated with a higher level of marital satisfaction and happiness. 
Table 2. Unadjusted and adjusted OR for marital satisfaction according to sociodemographic variables in Gonabad City, 2015

\begin{tabular}{|c|c|c|c|c|c|}
\hline Variable & Subgroups & Unadjusted OR & $\mathbf{P}$ & Adjusted OR ${ }^{*}$ & $\mathbf{P}$ \\
\hline \multirow{2}{*}{ Gender } & Female & 1.00 & - & 1.00 & - \\
\hline & Male & $1.41(0.98,2.02)$ & 0.063 & $1.82(1.003,3.29)$ & 0.049 \\
\hline \multirow[b]{2}{*}{ Age group, $y$} & $<45$ & 1.00 & - & & \\
\hline & $>45$ & $1.23(0.82,1.87)$ & 0.320 & & \\
\hline \multirow{3}{*}{ Education level } & Under diploma & 1.00 & - & & \\
\hline & Diploma & $1.1(0.71,1.69)$ & 0.671 & & \\
\hline & Academic & $1.15(0.74,1.79)$ & 0.536 & & \\
\hline \multirow{2}{*}{ Occupation } & Employed & 1.00 & - & 1.00 & - \\
\hline & Unemployed & $0.74(0.51,1.07)$ & 0.109 & $1.22(0.69,2.17)$ & 0.494 \\
\hline \multirow{3}{*}{ No. of children } & 0 & 1.00 & - & & \\
\hline & $1-2$ & $0.75(0.38,1.48)$ & 0.404 & & \\
\hline & $\geq 3$ & $0.79(0.39,1.6)$ & 0.508 & & \\
\hline \multirow{2}{*}{ Duration of marriage, $y$} & $<15$ & 1.00 & - & & \\
\hline & $>15$ & $1.13(0.79,1.63)$ & 0.497 & & \\
\hline \multirow{4}{*}{ Age at marriage, $y$} & $<21$ & 1.00 & - & 1.00 & - \\
\hline & $21-30$ & $1.05(0.68,1.62)$ & 0.835 & $0.93(0.56,1.56)$ & 0.792 \\
\hline & $31-40$ & $1.19(0.62,2.3)$ & 0.600 & $0.74(0.34,1.61)$ & 0.443 \\
\hline & $\geq 40$ & $3.08(0.68,13.94)$ & 0.145 & $0.98(0.19,5.15)$ & 0.981 \\
\hline \multirow{3}{*}{ Self-reported income } & Low & 1.00 & - & 1.00 & - \\
\hline & Moderate & $2.04(1.25,3.31)$ & 0.004 & $2.0(1.2,3.34)$ & 0.008 \\
\hline & High & $4.77(2.81,8.1)$ & $<0.001$ & $5.24(2.96,9.26)$ & $<0.001$ \\
\hline
\end{tabular}

*Adjusted odds ratio for all variables with the P-value of lower than 0.2 in the univariate model.

The present study revealed that subjects aged over 45 years were more likely to be satisfied with their marriage, however, this relationship was not significant. Many studies have shown the association between age and marital satisfaction [8, 14]. Some studies showed that age was negatively associated with marital satisfaction $[19,26]$.

Other variables, such as educational level, economic situation, number of children, and the length of marriage were not significant contributors to marital satisfaction. Furthermore, some studies have examined the relationship between education level and marital satisfaction. For example, Janssen (1988) found that women's higher education was a major contributor to marital instability [27]. However, some studies stated that women with higher education reported a lower rate of divorce [28] and higher marital satisfaction [14]. Rahmani also found no significant relationship between education level and marital satisfaction [19]. Moreover, the results of previous studies show a positive significant relationship between the length of the marriage and marital satisfaction, ie, 10 or more years of marriage was associated with a higher level of marital satisfaction [14]. Also, some studies argued that the length of the marriage was negatively associated with marital satisfaction [29, 30]. However, similar to the current study, Rahmani et al. found no sig- 
nificant relationship between the length of the marriage and marital satisfaction [19].

The findings of the previous studies suggested that low income and financial problems reduced marital satisfaction [23], whereas the rate of marital satisfaction was higher in high-income families $[14,21,22]$. The current study revealed no significant relationship between financial situations with marital satisfaction. In addition, no significant relationship was observed between the number of children and marital satisfaction. However, previous studies showed a negative correlation between marital satisfaction and the number of children [17, 31, 32]. This difference may be due to sociocultural differences. For example, in relatively traditional societies, family support can be fundamental to appropriately raise children and establish a successful marriage. The cultural value of having more children and childbearing persuasive policies to support parenthood can contribute to high levels of marital satisfaction in the presence of economic problems.

\section{Conclusion}

The findings of this study may help to protect the families and community's health. The results of this study and other similar studies can be used to establish premarriage counseling programs and prevent marital conflicts. Furthermore, the provision of legal and social rules and regulations to ensure the equal right of men and women, as well as attempts to improve the economic status of the families can lead to marital satisfaction and family solidarity.

\section{Limitations}

One of the limitations of this study was that the causal relationships should be warily done owing to the use of self-report measures and the lack of control for other variables. Besides, a few numbers of participants refused to complete the questionnaires and the responses were not assumed to be correct. Also, the present study examined the correlation between variables, and casual relationships were not taken into account.

\section{Recommendations}

We suggest further research to evaluate the determinants of self-differentiation, such as individualism and collectivism. Also, the effects of mediating factors, such as attachment styles, sexual satisfaction, and source control should be evaluated to accurately examine the relationship between self-differentiation, marital satisfac- tion, and happiness. Also, future research needs to use other testing techniques, such as clinical interviews and practical tests in different populations at different ages.

\section{Ethical Considerations}

\section{Compliance with ethical guidelines}

This study was approved by the Ethics Committee of the Gonabad University of Medical Sciences (IR.GMU. REC.1394.55)

\section{Funding}

This study was supported by the Social Development and Health Promotion Research Center, Gonabad University of Medical Sciences.

\section{Authors' contributions}

All authors equally contributed to preparing this article.

\section{Conflict of interest}

The authors declared no conflict of interest.

\section{References}

[1] Choi H, Marks NF. Marital conflict, depressive symptoms, and functional impairment. J Marriage Fam. 2008; 70(2):377-90 [DOI:10.1111/j.1741-3737.2008.00488.x] [PMID] [PMCID]

[2] Ebrahimi A, Jan Bozorgi M. [The relationship between communication skills and martital satisfaction (Persian)]. Ravanshenasi Va Din. 2008; 1(2):165-76. http://ensani.ir/fa/article/123640

[3] Lavner JA, Karney BR, Bradbury TN. Does couples' communication predict marital satisfaction, or does marital satisfaction predict communication? J Marriage Fam. 2016; 78(3):680-94 [DOI:10.1111/jomf.12301] [PMID] [PMCID]

[4] Shahbazi M, Khademali G. [The study and comparison of marital satisfaction, quality of life, happiness and life expectancy among married women with either less or more than five years of marital (Persian)]. J Appl Couns. 2018; 8(2):39-54 https://jac.scu.ac.ir/article_14054.html?lang=en

[5] Donoho CJ, Seeman TE, Sloan RP, Crimmins EM. Marita status, marital quality, and heart rate variability in the MIDUS cohort. J Fam Psychol. 2015; 29(2):290-5. [DOI:10.1037/ fam0000068] [PMID] [PMCID]

[6] Gottman JM, Levenson RW. The timing of divorce: Predicting when a couple will divorce over a 14-year period. J Marriage Fam. 2000; 62(3):737-45. [DOI:10.1111/j.17413737.2000.00737.x] 
[7] Laurenceau JP, Barrett LF, Rovine MJ. The interpersonal process model of intimacy in marriage: A daily-diary and multilevel modeling approach. J Fam Psychol. 2005; 19(2):31423. [DOI:10.1037/0893-3200.19.2.314] [PMID]

[8] Guo B, Huang J. Marital and sexual satisfaction in Chinese families: Exploring the moderating effects. J Sex Marital Ther. 2005; 31(1):21-9. [DOI:10.1080/00926230590475224] [PMID]

[9] Rostami A, Ghazinour M, Nygren L, Richter J. Marital satisfaction with a special focus on gender differences in medical staff in Tehran, Iran. J Fam Issues. 2014; 35(14): 1940-58. [DOI:10.1177/0192513X13483292]

[10] Wendorf CA, Lucas T, Imamoğlu EO, Weisfeld CC, Weisfeld GE. Marital satisfaction across three cultures: Does the number of children have an impact after accounting for other marital demographics? J Cross Cult Psychol. 2011; 42(3):340-54 [DOI:10.1177/0022022110362637]

[11] Wilson SJ, Bailey BE, Malarkey WB, Kiecolt-Glaser JK. Linking marital support to aging-related biomarkers: Both age and marital quality matter. J Gerontol B Psychol Sci Soc Sci. 2021; 76(2):273-82. [DOI:10.1093/geronb/gbz106] [PMID] [PMCID]

[12] Jose O, Alfons V. Do demographics affect marital satisfaction? J Sex Marital Ther. 2007; 33(1):73-85. [DOI:10.1080/00926230600998573] [PMID]

[13] Stack S, Eshleman JR. Marital status and happiness: A 17-nation study. J Marriage Fam. 1998; 60(2):527-36 [DOI:10.2307/353867]

[14] Zare B, Safyari Jafarabad H. [The study of marital satisfaction and its determinants on married women and men in Tehran city (Persian)]. J Women's Stud Sociol Psychol. 2015; 13(1):111-40. [DOI:10.22051/JWSPS.2015.1940]

[15] Talebi M, Ghobari Bonab B. [A study of the relationship of self-differentiation and emotional intelligence with investigating the relationship of self-differentialton and emotional intelligence with marital satisfaction in Shahroud counseling certers (Persian)]. Women Fam Stud. 2012; 5(18):15-32. http:/ / jwsf.iaut.ac.ir/article_519745.html?lang=en

[16] Arab Alidousti A, Nakhaee N, Khanjani N. [Reliability and validity of the persian versions of the enrich marital satisfaction (brief version) and kansas marital satisfaction scales (Persian)]. Health Dev J. 2015; 4(2):158-67. https://www.sid.ir/ fa/journal/ViewPaper.aspx?ID=246326

[17] Onyishi EI, Sorokowski P, Sorokowska A, Pipitone RN. Children and marital satisfaction in a non-Western sample: Having more children increases marital satisfaction among the Igbo people of Nigeria. Evol Hum Behav. 2012; 33(6):771-4. [DOI:10.1016/j.evolhumbehav.2012.06.005]

[18] Sorokowski P, Randall AK, Groyecka A, Frackowiak T, Cantarero K, Hilpert P, et al. Marital satisfaction, sex, age, marriage duration, religion, number of children, economic status, education, and collectivistic values: Data from 33 countries. Front Psychol. 2017; 8:1199. [DOI:10.3389/fpsyg.2017.01199] [PMID] [PMCID]

[19] Rahmani A, Merghati Khoei E, Sadeghi N, Merghati Khoei E, Allahgholi L. [Relationship between Sexual pleasure and Marital Satisfaction (Persian)]. Iran J Nurs. 2011; 24(70):8290. http://ijn.iums.ac.ir/browse.php?a_id=988\&slc_ lang $=$ en\&sid $=1$
[20] Qian Y, Sayer LC. Division of labor, gender ideology, and marital satisfaction in East Asia. J Marriage Fam. 2016; 78(2):383-400. [DOI:10.1111/jomf.12274]

[21] Pimentel EE. Just how do I love thee?: Marital relations in Urban China. J Marriage Fam. 2000; 62(1):32-47. [DOI:10.1111/j.1741-3737.2000.00032.x]

[22] Trudel G. Sexuality and marital life: Results of a survey. J Sex Marital Ther. 2002; 28(3):229-49. [DOI:10.1080/009262302 760328271] [PMID]

[23] Lichter DT, Carmalt JH. Religion and marital quality among low-income couples. Soc Sci Res. 2009; 38(1):168-87. [DOI:10.1016/j.ssresearch.2008.07.003]

[24] Mousavi AS. [Comparision of different strains of marital satisfaction in employed and housewives (Persian)]. J Women Study (Sociol Psychol ). 2006; 4(2):71-88. http:/ / ensani.ir/ file/download/article/20100609110539-

[25] Hadyian Z. [Investigating the relationship between waiting expectation and satisfaction with marital life among married women in Tehran (Persian)] [MA. thesis]. Tehran: Alzahra University; 2007.

[26] Lee GR, Shehan CL. Retirement and marital satisfaction. J Gerontol. 1989; 44(6):S226-30. [DOI:10.1093/geronj/44.6.S226] [PMID]

[27] Moradi M. The investigation of the marriage and divorce status in Tabriz. J Hist Cult Art Res. 2017; 6(2):36-50. [DOI:10.7596/taksad.v6i2.848]

[28] Heaton TB. Factors contributing to increasing marital stability in the United States. J Fam Iss. 2002; 23(3):392-409. [DO:10.11 77/0192513X02023003004]

[29] Margelisch K, Schneewind KA, Violette J, Perrig-Chiello P. Marital stability, satisfaction and well-being in old age: Variability and continuity in long-term continuously married older persons. Aging Ment Health. 2017; 21(4):389-98. [DOI:10.1080 /13607863.2015.1102197] [PMID]

[30] Bakhshayesh AR, Mortazavi M. [The relationship between sexual satisfaction, general health and marital satisfaction in couples (Persian)]. J Appl Psychol. 2010; 3(4):73-85. https:// www.sid.ir/fa/journal/ViewPaper.aspx?id=114603

[31] Twenge JM, Campbell WK, Foster CA. Parenthood and marital satisfaction: A meta-analytic review. J Marr Fam. 2003; 65(3):574-83. [DOI:10.1111/j.1741-3737.2003.00574.x]

[32] Balsamo DL, Deese MA, Keifer JG, Armstrong PJ. Marital satisfaction in relation to age and number of children. Paperpresented at: $18^{\text {th }}$ Annual Reseach Conference. 2-4 April 2013; Dahlonega, Georgia, United State. https://digitalcommons. northgeorgia.edu/ngresearchconf/2013/GenderStudies/2/ 
This Page Intentionally Left Blank 